\title{
LÍPIDES PLASMÁTICOS EM RATOS APÓS CIRURGIA ESPLÊNICA - EFEITO DE DOIS TIPOS DE DIETA
}

Isabel Cristina Andreatta lemos Paulo*, Danilo Nagib Salomáo Paulo, Mitre Kalil, Alvino Jorge Guerra, Eduardo Almeida Guerzet, Alcino Lázaro da Silva

Trabalho realizado no Laboratório de Fundamentos da Cirurgia da Escola Superior de Ciências da Santa Casa de Misericórdia de Vitória/ES

* Correspondência:

Rua Santa Rita de Cássia, 777

Bairro de Lourdes, Vitória/ES

Cep: $29042-753$

Tels: (27) 3323-4827 /

(27) $3222-1545$

icpaulo@unimedvitoria.com.br

\section{RESUMO}

OвJetivo. Verificar o efeito da esplenectomia total e da ligadura dos vasos esplênicos principais nos lípides plasmáticos de ratos alimentados com dieta controle ou dieta acrescida de 2,5\% de colesterol.

Métodos. Foram utillzados 99 ratos Wistar, machos, pesando entre 273 g e 427 g (MA 349,46; DP 35,54), distribuídos aleatoriamente em quatro grupos: grupo I, controle $(n=19)$, não operado; grupo $2(n=19)$, manipulação do baço; grupo $3(n=31)$, esplenectomia total; grupo $4(n=30)$, ligadura simultânea da artéria e veia esplênicas. Após a dosagem dos lípides plasmáticos, os ratos foram distribuídos em dois subgrupos, de acordo com a dieta prescrita após o início do experimento (subgrupo A, dieta controle; subgrupo B, dieta acrescida de 2,5\% de colesterol). Depois de 90 dias, foi realizada nova coleta de sangue para dosagem de lípides.

Resultados. Não houve differenças significantes nos níveis de lípides entre os quatro grupos, no início do experimento $(p>0,05)$. Nos subgrupos $I A, 2 A$ e $4 A$, não ocorreram alterações significantes da HDL-colesterol, da VLDL-colesterol e trigicérides. A LDL-colesterol caiu significantemente nos subgrupos $I A$ e 2 A $(p<0,05)$, e não significantemente no $4 \mathrm{~A}$ $(p>0,05)$. Nos subgrupos IB, $2 B$ e 4B, houve aumento significante do colesterol total, LDL-colesterol, VLDL-colesterol $(p<0,05)$, e não significante da HDL-colesterol. No grupo 3, houve aumento significante dos lípides $(p<0,01)$, principalmente no subgrupo 3B, exceto a HDL-colesterol, cujo aumento não foi significante. Nesse grupo, o colesterol total e a LDL-colesterol foram significantemente maiores que os dos grupos I, 2 e 4 .

Conclusäo. A esplenectomia total provoca aumento do colesterol total, da LDL-colesterol, da VLDL-colesterol e dos triglicérides, que é mais significante nos animais alimentados com a dieta acrescida de colesterol. A ligadura simultânea da artéria e da veia esplênicas previne contra as alteraç̧oes dos níveis de lípides plasmáticos observadas em ratos submetidos à esplenectomia total e mantém esses níveis similares aos dos grupos controle e simulação.

Unitermos: Baço / metabolismo. Esplenectomia / efeitos adversos. Esplenectomia / métodos. Ligadura da artéria esplênica. Ligadura da veia esplênica.

\section{INTRODUÇão}

A esplenectomia total pode induzir complicações locais e sistêmicas'. Dessas, a mais temida é a infecção pós-esplenectomia ${ }^{23.3}$. As complicações infecciosas após a retirada do baço foram também descritas em animais de experimentaçãa $0^{4,5}$. Além dessas complicações, têm sido relatadas, após esplenectomia, alterações no metabolismo lipídico, tanto em seres humanos ${ }^{6-8}$ quanto em animais de experimentaçãa ${ }^{9-13}$. Por essas razões, têm sido cada vez mais valorizadas as operações conservadoras sobre o baço. Nesse contexto, incluem-se as ligaduras vasculares. A ligadura da artéria esplênica é realizada como coadjuvante do tratamento do trauma esplênico| ${ }^{4,15}$, no combate à hipertensão porta ${ }^{16} \mathrm{e}$ ao aneurisma da artéria esplênica ${ }^{17}$. Em ratos normais, a ligadura da artéria esplênica reduz a massa funcional do baço ${ }^{18}$; combate o hiperesplenismo induzido por ligadura da veia esplênica ${ }^{18,19} \mathrm{e}$ a hipertensão porta ${ }^{20}$; aumenta a susceptibilidade de infecção por pneumococo, quando comparada a um grupo simulação ${ }^{21}$; e diminui a mortalidade por septicemia pneumocócica, quando associada à infusão de solução salina e comparada à esplenectomia ${ }^{22}$. Em cães, a ligadura de ramos da artéria esplênica contribui para a indução de pancreatite crônica ${ }^{23}$, mas protege o animal de infecção por pneumococo, quando associada à exérese do pólo inferior do baço ${ }^{24}$. A ligadura da artéria esplênica em coelhos diminui a resposta imune à administração intravenosa de antígenos morfologicamente modelados $^{25}$.

A ligadura simultânea da artéria e da veia esplênicas, com preservação do baço, em seres humanos, foi realizada na pancreatectomia caudal por laparatomia ${ }^{26,27}$ e por via laparoscópica ${ }^{28}$. As consequêencias para o baço dessa ligadura simultânea foram recentemente descritas ${ }^{29}$. Não se sabe o efeito dessa ligadura nem de diferentes dietas sobre os níveis de lípides plasmáticos, em ratos. Por essas razões, planejamos estudar os efeitos da ligadura simultânea da artéria e veia esplênicas e da esplenectomia total sobre os níveis de lípides plasmáticos de ratos adultos, alimentados com dieta controle ou com dieta acrescida de 2,5\% de colesterol. 
Paulo ICAL et al.

\section{Métodos}

Os procedimentos foram aprovados pelo Comitê de Ética em Pesquisa da Escola Superior de Ciências da Santa Casa de Misericórdia de Vitória/ES (Protocolo n 002/2004).

Foram utilizados 99 ratos, Wistar, machos, com peso entre 273 g e 427 g (MA 349,46; DP 35,54). Os animais foram alocados em gaiolas coletivas, com capacidade para seis animais, onde eram alimentados, antes do experimento, com ração comercial granulada para animais de laboratório (Moinho Primor MP-77, São Paulo). Nessa ocasião, foram submetidos a exame clínico para descartar possíveis afecções.

Após um período de adaptação de 15 dias, os ratos foram distribuídos aleatoriamente em quatro grupos: grupo | $(n=\mid 9)$, controle (não operado); grupo $2(n=19)$, simulado (manipulação esplênica); grupo $3(n=3 \mid)$, esplenectomia total; grupo 4 $(n=30)$, ligadura simultânea da artéria e da veia esplênicas com preservação do baço.

Após um jejum de 12 horas, foi colhido de cada animal I,2 ml de sangue, por punção cardíaca transtorácica, para dosagem dos lípides plasmáticos (colesterol total, HDL-colesterol, LDL-colesterol, VLDL-colesterol e triglicérides). Antes da punção, os ratos foram submetidos à anestesia superficial com éter etílico e pesados (balança eletrônica Filizola, São Paulo/SP, Brasil), com sensibilidade de I g. A seguir, foram identificados com uma marca na orelha e devolvidos às suas gaiolas de origem. A dosagem dos lípides foi feita no aparelho Dimension AR Dade Behring (Deerfield, IL, USA).

Iniciado o experimento, os animais do grupo I foram mantidos em suas gaiolas e passaram a receber dieta controle (subgrupo A) ou acrescida de 2,5\% de colesterol (subgrupo B) e água à vontade. A dieta com colesterol foi manipulada adicionando-se $25 \mathrm{~g}$ de colesterol puro a cada kg de ração controle, preparada especialmente para o experimento (Tabela I). O colesterol puro foi obtido a partir da lã de ovelhas, lanolina, importado da Holanda, gentilmente doado pela Agribrands do Brasil (Paulínia/SP). As dietas foram manipuladas pela Du Milho Indústria e Comércio (Viana, Espírito Santo, Brasil) e fornecida a título de cortesia para a pesquisa.

Nos animais dos grupos operados ${ }^{2,3,4}$, a seqüência operatória foi a seguinte: indução anestésica com vapores de éter etílico; depilação das paredes abdominal e torácica ventral; anti-sepsia das paredes abdominal e torácica ventral com álcool iodado, e colocação de um campo operatório para delimitar o local da laparotomia; incisão longitudinal, mediana, da pele e subcutâneo, com cerca de $2,5 \mathrm{~cm}$ de comprimento, iniciada $0,5 \mathrm{~cm}$ abaixo do processo xifóide em direção ao púbis; abertura da linha alba e peritônio; e exame da cavidade abdominal.

Cada grupo foi submetido à cirurgia proposta, conforme exposto a seguir. No grupo 2, foi realizada apenas a manipulação do baço. No grupo 3, foi realizada a esplenectomia total na seguinte seqüência: o estômago foi tracionado para fora da cavidade abdominal e, assim, o baço foi exposto; três ligaduras rentes ao baço permitiram a secção dos vasos e a retirada desse órgão. No grupo 4, o baço foi rebatido para cima, a fim de expor o pâncreas e identificar os vasos esplênicos. Foi realizada dupla ligadura simultânea da artéria e da veia esplênicas, cerca de I,4 cm da borda hilar, com fio mononáilon 4.0, conforme a técnica já descrita ${ }^{29}$.

\begin{tabular}{|c|c|}
\hline \multicolumn{2}{|c|}{$\begin{array}{c}\text { Tabela I - Dietas utilizadas nos subgrupos A e B } \text { B }^{3} \text { Composição } \\
\text { centesimal da ração basal para ratos }\end{array}$} \\
\hline Ingredientes & $\%$ \\
\hline $\begin{array}{l}\text { Milho moído } \\
\text { Farelo de soja, 45\% } \\
\text { Farelo de Trigo } 15 \% \\
\text { Óleo de soja } \\
\text { Fosfato bicálcico, 18\% } \\
\text { Calcário 38\% } \\
\text { Sal comum (cloreto de sódio) } \\
\text { DI-metionina 99\% } \\
\text { Suplemento mineral' } \\
\text { Suplemento de vitamina² } \\
\text { L-Lisina.Hcl 78\% } \\
\text { Cloreto de colina 60\% } \\
\text { BHT (antioxidante) } \\
\text { Total }\end{array}$ & $\begin{array}{l}54,90 \\
29,00 \\
10,00 \\
2,50 \\
1,60 \\
1,34 \\
0,40 \\
0,11 \\
0,05 \\
0,03 \\
0,03 \\
0,03 \\
0,01 \\
100,00\end{array}$ \\
\hline $\begin{array}{l}\text { Composição química pro } \\
\text { Energia metabolizável, Kcal/Kg } \\
\text { Proteína bruta, \% } \\
\text { Fibra bruta, \% } \\
\text { Gordura, \% } \\
\text { Matéria mineral, \% } \\
\text { Cálcio, \% } \\
\text { Fósforo total, \% } \\
\text { Metionina,\% } \\
\text { Aminioácidos sulfurados, \% } \\
\text { Lisina, \% } \\
\text { Triptofano, \% } \\
\text { Treonina, \% } \\
\text { Arginina,\% } \\
\text { Valina,\% } \\
\text { Isoleucina, \% } \\
\text { Histidina, \% } \\
\text { Fenilalanina, \% }\end{array}$ & $\begin{array}{c}3.000 .00 \\
19,00 \\
4,40 \\
5,00 \\
6,10 \\
1,00 \\
0,70 \\
0,41 \\
0,76 \\
1,00 \\
0,24 \\
0,72 \\
1,26 \\
1,01 \\
0,94 \\
0,48 \\
0,96\end{array}$ \\
\hline
\end{tabular}

I: Fornece por Kg de raçẵo em mg: ferro 40; zinco 60; cobre 16; manganês 20; iodo 50; selênio 0,25 2: Fornece por Kg de ração: vitamina A $7000 \mathrm{Ul}$; vitamina D3 $1000 \mathrm{Ul}$; vitamina E $30 \mathrm{mg}$; vitamina K I mg; tiamina $4 \mathrm{mg}$; riboflavina $4 \mathrm{mg}$; ácido pantotênico $15 \mathrm{mg}$; niacina $30 \mathrm{mg}$; piridoxina $6 \mathrm{mg}$; ácido fólico $0,5 \mathrm{mg} ;$ biotina $0,15 \mathrm{mg}$; vitamina $\mathrm{B} 120,01 \mathrm{mg}$.

3: A dieta dos animais do subbrupo B teve a mesma composição básica. Para cada Kg de ração, foram adicionadas $25 \mathrm{~g}$ de colesterol puro (100\%), obtido da lâ de ovehas (lanolina), importado da Holanda e doado pela Agribrands do Brasil para este experimento

A parede abdominal foi suturada em dois planos, com mononáilon 4.0, chuleio simples: no primeiro, o peritônio e o plano músculo aponeurótico e, no segundo, a pele. Após recuperação anestésica, os animais foram devolvidos às suas gaiolas, onde recebiam dieta controle (subgrupo $A$ ) ou acrescida de 2,5\% de colesterol (subgrupo B) e água à vontade. Foi feita nova coleta de sangue, 90 dias após, com os mesmos cuidados do início do experimento, para dosagem dos lípides plasmáticos. Após a coleta, os ratos foram mortos com dose letal de éter etílico. Nessa ocasião, o rato foi pesado e feita uma incisão em $U$ invertido na parede abdominal para exame da cavidade abdominal, do baço e das outras vísceras abdominais. Esse órgão foi retirado, pesado, fotografado; 
foi avaliado o seu aspecto macroscópico, e fixado em formol a 4\%. Após a fixação, os baços foram pesados, com precisão de 0,00। g. Nos animais do grupo 4, foi calculado o percentual médio de massa viável do remanescente esplênico. Os fragmentos do baço foram incluídos em parafina, e os cortes corados pela hematoxilina e eosina. No exame microscópico, procurou-se verificar, principalmente, aspectos relativos à viabilidade esplênica.

O teste $t$ de Student para amostras relacionadas foi utilizado para comparar os valores de pré-operatório com os de pós-operatório dos lípides plasmáticos dentro de um mesmo grupo. O teste de Kruskal Wallis, para comparar os valores dos lípides entre grupos diferentes. $O$ percentual médio de massa remanescente do grupo 4 foi calculado, dividindo-se o peso da porção remanescente pelo peso ideal do baço para cada animal, multiplicando-se o resultado por 100. Foi obtida a média do percentual da massa viável do baço com o respectivo desvio padrão dos dois grupos. $O$ cálculo do peso ideal do baço foi feito utilizando-se a fórmula: peso do baço $=1,8$ $x$ peso corporal $+230,49$, obtida a partir da análise de regressão linear dos pesos dos baços em função do peso corporal nos animais do grupo controle. Um valor $p<0,05$ foi considerado estatisticamente significante.

\section{Resultados}

Houve aumento do peso dos animais em todos os grupos. 0 peso médio percentual do remanescente esplênico nos animais do grupo submetido à ligadura da artéria e da veia esplênicas foi $49,21 \% \pm 3,53 \%$. No grupo de animais esplenectomizados, constatamos II óbitos cujas causas não foram encontradas. Os exames da cavidade abdominal e torácica nos animais que faleceram, bem como a cultura de sangue, de tecido pulmonar e hepático não identificaram a possível causa de óbito. Observamos deiscência parcial da sutura da pele em dois animais do grupo esplenectomia total. Houve cinco óbitos no grupo da ligadura simultânea da artéria e da veia esplênicas (grupo 4B). Esses 16 animais que faleceram foram excluídos da análise estatística.

O aspecto da cavidade abdominal foi normal nos animais do grupo 1. Nos animais do grupo 2, foram observadas aderências frouxas entre o baço e o estômago e o fígado e a parede abdominal. Nos animais do grupo 3, as aderências estavam presentes entre 0 estômago, fígado e a parede abdominal. Nos animais do grupo 4, as aderências eram mais freqüentes, intensas e firmes e ocorriam entre o baço e o figado, intestino delgado, estômago e rim esquerdo. Em alguns casos, as vísceras aderentes envolviam totalmente o baço.

O baço apresentou-se normal em todos os casos dos grupos I, 2 e 3 e em três dos 25 casos do grupo 4 (12\%). Nos demais ratos do grupo 4, a porção superior do baço estava íntegra, e havia uma formação pediculada na porção inferior desse órgão em 17 casos, ou na porção média em cinco casos (Figura I).

Nos animais não operados (grupo I), alimentados com dieta controle, ocorreu diminuição significante dos níveis de colesterol total, à custa, principalmente, da fração LDL-colesterol $(p<0,05)$ (Figura 2). Os níveis de HDL-colesterol, VLDL-colesterol e triglicérides não sofreram alterações significantes. Nos alimentados
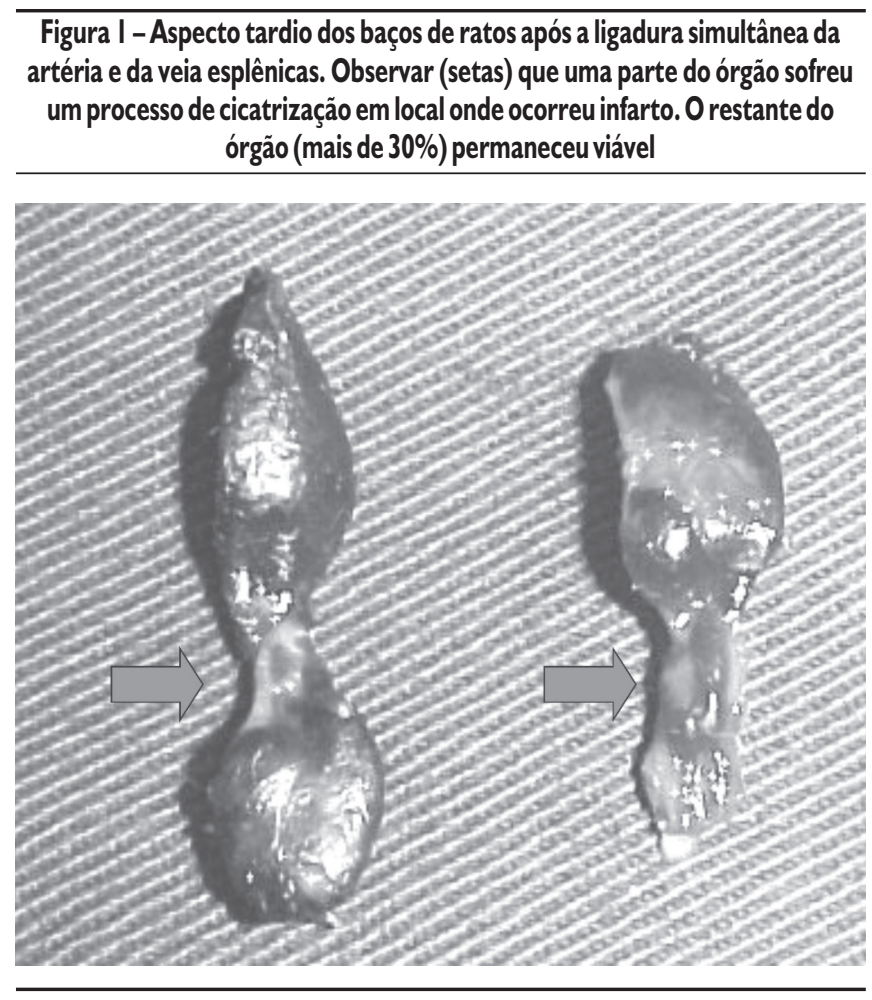

com dieta acrescida de $2,5 \%$ de colesterol, houve aumento significante do colesterol total $(\mathrm{p}<0,01)$, à custa principalmente da VLDL-colesterol $(p<0,01)$. A HDL tendeu a cair $(p=0,059)$, os triglicérides aumentaram significantemente $(p<0,01)$, e a LDLcolesterol não sofreu alterações significantes $(p>0,05)$ (Figura 2).

Nos animais submetidos à manipulação do baço (grupo 2), alimentados com dieta controle, houve diminuição do colesterol total graças, principalmente, à queda significante da LDL-colesterol (Figura 2). Os níveis de HDL-colesterol, VLDL-colesterol e triglicérides não sofreram alterações significantes. Nos alimentados com dieta acrescida de 2,5\% de colesterol, houve aumento significante do colesterol total $(p<0,01)$, à custa da VLDLcolesterol $(p<0,0 I)$ e da LDL-colesterol $(p<0,05)$. A HDLcolesterol não sofreu alterações significantes. Os triglicérides aumentaram significantemente $(p<0,01)$. No início do experimento, quando o grupo simulado e o grupo não operado se alimentavam com dieta granulada, não houve diferença significante nos níveis de lípides entre esses grupos $(p>0,05)$. No final do experimento, os níveis de colesterol total e frações no grupo de animais alimentados com dieta controle ou acrescida de 2,5\% de colesterol não apresentaram diferença estatisticamente significante. Isso mostra que os grupos I e 2 são semelhantes e que a operação simulada não interferiu nos resultados.

Nos ratos submetidos à esplenectomia total (grupo 3), houve aumento significante do colesterol total no pós-operatório tardio, independentemente do tipo de dieta utilizada $(p<0,01)$ (Figura 2). Esse aumento no subgrupo $3 \mathrm{~A}$ ocorreu por aumento significante 
Figura 2 - Lípides plasmáticos nos animais alimentados com dieta controle ou com dieta acrescida de 2,5\% de colesterol. As colunas representam a média aritmética e desvio padrão
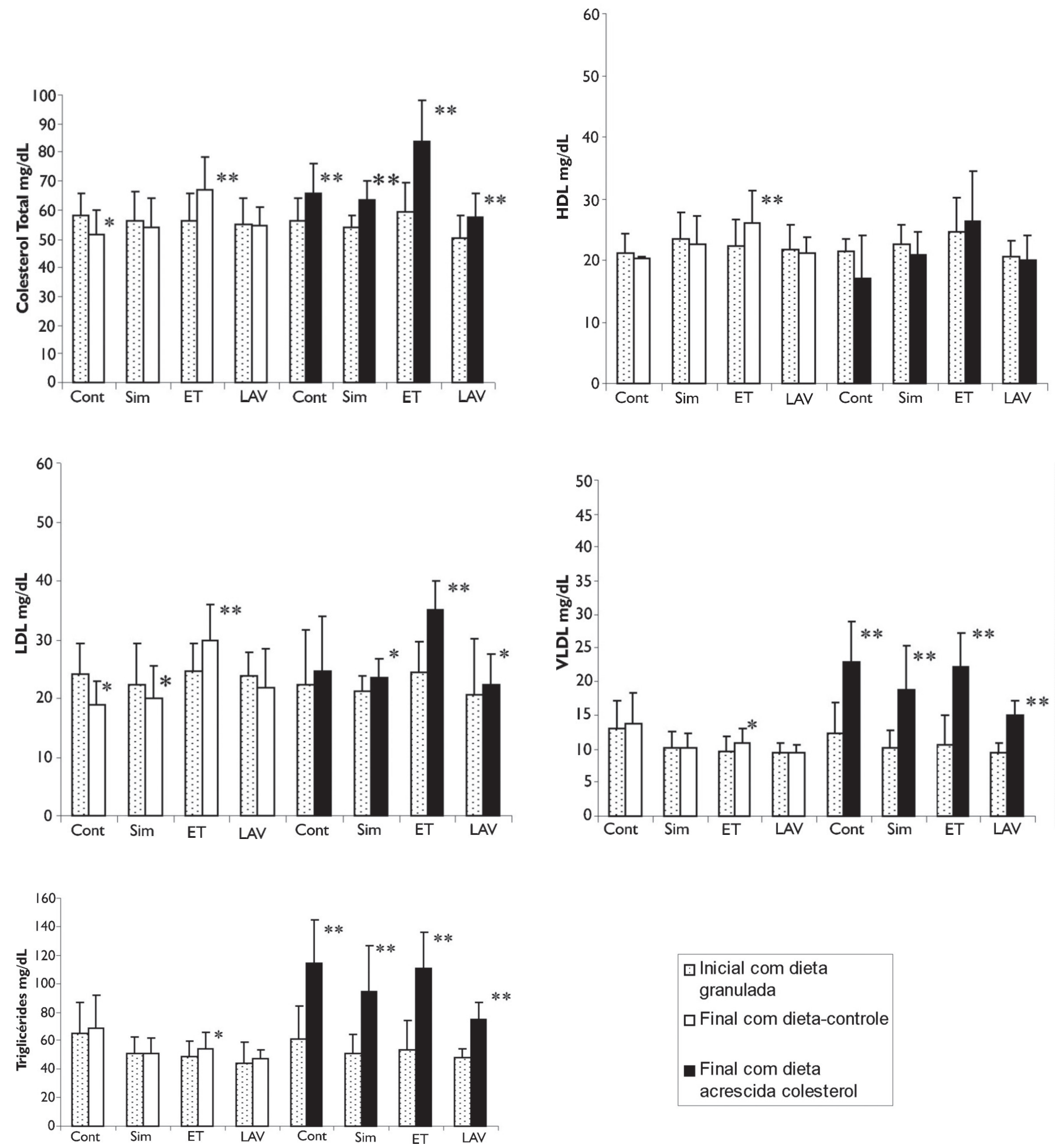

Cont: controle; Sim: simulação; ET: esplenectomia total; LAV: ligadura da artéria e veia esplênicas; *: $p<0,05$; **: $p<0,01$ (Teste t de Student para amostras relacionadas) 
das três frações, e no subgrupo 3B, graças ao aumento significante das frações LDL-colesterol e VLDL-colesterol. Houve aumento significante dos triglicérides nos dois subgrupos (Figura 2). 0 colesterol total, LDL-colesterol, VLDL-colesterol e triglicérides sofreram aumento mais significante no subgrupo $3 \mathrm{~B}$ do que no $3 \mathrm{~A}$. No final do experimento, os níveis de colesterol total foram significantemente maiores no subgrupo $3 A$ do que no subgrupo IA às custas, principalmente, da HDL-colesterol e da LDL-colesterol $(p<0,0 I)$. Os níveis de VLDL-colesterol e triglicérides não diferiram entre esse dois grupos. No subgrupo 3B, os níveis de colesterol total foram significantemente maiores do que no subgrupo IB (não operado) $(p<0,05)$. Esse aumento ocorreu às custas, principalmente, da LDL-colesterol $(p<0,0 I)$ e da HDL $(p<0,0 \mid$ ), no final do experimento. Não houve diferenças entre esses dois subgrupos no início do experimento, quando usavam a dieta granulada. A VLDL-colesterol e triglicérides não diferiram entre os dois grupos, tanto no início quanto no final do experimento. Os níveis de colesterol total nos subgrupos $3 \mathrm{~A}$ e $3 \mathrm{~B}$ foram significantemente maiores do que no grupo simulação $(2 A, 2 B)(p<0,01)$, às custas principalmente da fração LDL-colesterol $(p<0,01)$. A VLDL-colesterol e triglicérides não diferiram entre os dois grupos.

Nos animais submetidos à ligadura simultânea da artéria e veia esplênicas (grupo 4), alimentados com dieta controle, os níveis de colesterol e frações e triglicérides no pós-operatório tardio não sofreram variações significantes (Figura 2). Nos animais alimentados com dieta acrescida de 2,5\% de colesterol, os níveis de colesterol aumentaram significantemente graças ao aumento significante da VLDL-colesterol $(p<0,0 I)$ e LDL-colesterol $(p<0,0 I)$. Os triglicérides também aumentaram significantemente nesse subgrupo $(p<0,01)$. Os níveis de colesterol total no grupo da ligadura foram semelhantes aos do grupo não operado, em animais alimentados com dieta controle no final do experimento. A fração VLDL-colesterol foi significantemente menor no subgrupo $4 A$ em relação ao subgrupo $\mid A(p<0,0 \mid)$ e as frações HDL-colesterol e LDL-colesterol foram maiores no subgrupo 4A. Isso manteve os níveis de colesterol semelhantes entre os dois subgrupos. Os níveis de triglicérides foram maiores no final do experimento no subgrupo IA em relação ao 4A. Não houve alterações significantes nos triglicérides do início para o final do experimento, tanto no subgrupo IA quanto no subgrupo 4A $(p>0,05)$ (Figura 2). Nos animais alimentados com dieta acrescida de 2,5\% de colesterol, as variações dos níveis de colesterol total, VLDL-colesterol e triglicérides no grupo ligadura foram semelhantes às do grupo não operado $(p<0,05)$. A LDL-colesterol aumentou mais no subgrupo $4 \mathrm{~B}$ do que no IB. Os níveis de lípides no grupo da ligadura foram semelhantes ao grupo simulado, independentemente do tipo de dieta, no final do experimento. Mas a VLDLcolesterol no final do experimento foi menor no grupo 4B do que no I B. Os níveis de colesterol total no grupo da esplenectomia total foram significantemente maiores que os níveis de colesterol total no grupo da ligadura, tanto no subgrupo $4 A(p<0,05)$ quanto no subgrupo $4 B(p<0,01)$. Nos animais alimentados com dieta controle, o aumento ocorreu graças às frações LDL-colesterol e HDLcolesterol, e nos alimentados com dieta acrescida de 2,5\% de colesterol, graças à $L D L$-colesterol $(p<0,01)$ e à $V L D L$-colesterol $(p<0,01)$. Os triglicérides também foram significantemente maiores no grupo da esplenectomia total $(p<0,0 \mathrm{I})$.

\section{Discussão}

As aderências abdominais pós-operatórias ocorreram em todos os grupos operados. No grupo em que se fez a ligadura simultânea da artéria e da veia esplênicas, as aderências eram firmes, freqüentes, envolvendo o baço e vísceras abdominais, o que confirma que a isquemia é um fator provocador de aderências ${ }^{30}$.

O baço apresentou-se macroscopicamente normal nos animais dos grupos 1, 2 e 3. Nos ratos do grupo 4, houve formação de uma porção pediculada na porção inferior do órgão em 13 casos e na porção média em três casos, a qual, porção pediculada, substituía a zona de infarto branco. Esse mesmo tipo de lesão foi observado por Paulo et al. ${ }^{29}$, quando realizaram ligadura simultânea da artéria e da veia esplênicas em ratos. Touloukiam et al. ${ }^{31}$, realizando ligadura parcial do pedículo esplênico em ratos, observaram necrose do baço e de regiões vizinhas. Entretanto, ocorreu cicatrização após um mês, e a função do baço se alterou apenas transitoriamente. Após dois meses, o baço se apresentou normal. Em nosso experimento, a ligadura dos vasos esplênicos produziu no baço necrose seguida de cicatrização da porção inferior ou média, conforme foi demonstrado. E possível que, logo após a ligadura dos vasos esplênicos, tenha ocorrido alteração no níveis de lípides plasmáticos, mas em 90 dias houve manutenção dos níveis lipídicos, conforme os nossos resultados.

Se confrontamos os níveis de lípides, no início do experimento, entre os quatro grupos, quando os animais se alimentavam com dieta granulada, verificamos que não houve diferença estatisticamente significante $(p>0,05)$. Esse fato não se repetiu no final do experimento em alguns casos, quando houve diferença significante. Isso pode ser atribuído aos procedimentos executados durante 0 transoperatório (operações) e pós-operatório (dietas, observação - grupo I).

Quando comparamos os níveis de lípides no final do experimento, verificamos que eles não diferiram entre os subgrupos IA e $2 A$, e os subgrupos IB e $2 B$. Os níveis de colesterol total foram significantemente maiores nos animais alimentados com dieta acrescida de 2,5\% de colesterol, à custa da VLDL-colesterol. Esses resultados mostram que esses grupos são similares e que a operação simulada não interfere nos níveis de lípides, mas a dieta com colesterol sim. A dieta controle parece benéfica, porque os animais alimentados com ela tiveram diminuição do colesterol total à custa da LDL-colesterol. A dieta com colesterol não parece benéfica, porque os animais alimentados com ela tiveram aumento significante do colesterol à custa da VLDL-colesterol.

Quando analisamos as variações dos níveis de lípides nos ratos submetidos à esplenectomia total, verificamos que a retirada de todo o baço produz aumento desses lípides, confirmando as observações da literatura ${ }^{7.13}$. É importante ressaltar que, no grupo não operado, houve diminuição significante dos níveis de colesterol $(p=0,02)$; e, no grupo esplenectomia total, houve aumento significante desse lípide $(p=0,009)$, nos animais alimentados com dieta controle. Podese observar que um dos componentes dessa dieta é a soja e que a proteína da soja é capaz de diminuir o colesterol total e a fração LDLcolesterol. O efeito dessa proteína é intensificado pela isoflavona, presente na soja em quantidade variável ${ }^{32}$. Esse fato reforça a afirmativa de que, de fato, a retirada do baço em ratos produz aumento do 
PAULO ICAL ET AL.

colesterol. A dieta acrescida de 2,5\% de colesterol contribui para aumentar os níveis de colesterol nesses animais esplenectomizados, porque os níveis de colesterol total foram significantemente maiores no subgrupo $3 \mathrm{~B}$ do que no subgrupo $3 \mathrm{~A}$. De sorte que tanto a esplenectomia total quanto a dieta acrescida de $2,5 \%$ de colesterol aumentam os níveis de colesterol total, LDL-colesterol, VLDLcolesterol e triglicérides. Aliás, já foi relatado em trabalhos clínicos e experimentais que a esplenectomia provoca aumento do colesterol, bem como a dieta, e que os níveis de triglicérides em ratos esplenectomizados não se alteram ${ }^{12,13}$. Em nosso experimento houve aumento de triglicérides nos animais esplenectomizados. $\mathrm{O}$ aumento significante da LDL-colesterol e triglicérides em animais esplenectomizados alimentados com dieta com colesterol foi também observado por Fatouros et al. ${ }^{9}$, que usaram dieta com colesterol em ratos. Em nossa pesquisa, o aumento da LDL-colesterol e dos triglicérides ocorreu nos animais esplenectomizados, independentemente do tipo de dieta. Isso nos leva a supor que a retirada do baço foi o fator decisivo para essa alteração.

A análise das variações dos níveis de lípides nos ratos submetidos à ligadura simultânea da artéria e da veia esplênicas mostrou que essa operação não causa alterações significantes nos níveis desses lípides. Cumpre ressaltar que esses níveis foram significantemente menores do que no grupo da esplenectomia total e que foram semelhantes aos dos grupos controle e simulação. Esses dados nos levam a admitir que a ligadura simultânea da artéria e da veia esplênicas protege o animal da elevação dos níveis de colesterol, tanto nos animais alimentados com dieta controle quanto nos alimentados com dieta acrescida de 2,5\% de colesterol. 0 remanescente esplênico das ligaduras vasculares é capaz de manter próximos ao normal os níveis de lípides.

Bradshaw e Thomas ${ }^{33}$ relataram que, quanto maior o remanescente esplênico, maior a proteção contra a sepse, e calcularam em 25\% a massa crítica de tecido esplênico residual para se ter função fagocitária normal. Esse relato é consenso da maioria dos autores que defendem que a massa crítica mínima necessária para manter a função esplênica deve ser superior a 25\% da massa esplênica total. Van Wick et al. ${ }^{34}$, em trabalho experimental em ratos, consideraram necessária a manutenção de um terço do tecido esplênico total, para restaurar a função esplênica. Em nosso experimento, o peso médio percentual do remanescente esplênico, no grupo da ligadura simultânea da artéria e da veia, foi de 49,21\%. É de se esperar, portanto, que o remanescente esplênico nas referidas operações conservadoras proteja o organismo das elevações dos lípides plasmáticos, conforme demonstramos.

Na tentativa de explicar o mecanismo pelo qual o baço interfere no metabolismo lipídico, Caligiuri et al, ${ }^{35}$ sugeriram a participação do sistema imunológico mediado por linfócitos B no controle da LDL colesterol. Os linfócitos B seriam capazes de produzir anticorpos contra a LDL-colesterol-oxidado, e o complexo LDL-colesteroloxidado mais o anticorpo seriam captados por receptores dos macrófagos do baço. Daí ocorreria a fagocitose com destruição do complexo, tanto no nível local, nas placas de ateroma, quanto no nível sistêmico, no baço. A esplenectomia total levaria a um desequilíbrio na captação do complexo antígeno-anticorpo. Isso explicaria o aumento da LDL-colesterol encontrado em animais esplenectomizados. O aumento dos níveis de triglicérides observados por Hartmut e Siegfried ${ }^{36}$ e por Fatouros et al. ${ }^{10}$ e a queda dos níveis de HDL-colesterol encontrados por Fatouros et al..$^{10}$ e Silva et al. ${ }^{12}$ se devem provavelmente ao tipo de dieta utilizada. Em nosso trabalho, os animais que se alimentaram de dieta com 2,5\% de colesterol tiveram aumento significante dos triglicérides, LDLcolesterol e VLDL-colesterol e queda da HDL-colesterol no grupo simulado. No grupo da esplenectomia total, houve aumento da LDL-colesterol independentemente da dieta.

\section{CONCLUSÃo}

A esplenectomia total provoca aumento do colesterol total, da LDL-colesterol, da VLDL-colesterol e dos triglicérides, que é mais significante nos animais alimentados com a dieta acrescida de colesterol. A ligadura simultânea da artéria e da veia esplênicas previne contra as alterações dos níveis de lípides plasmáticos observadas em ratos submetidos à esplenectomia total e mantém esses níveis similares aos dos grupos controle e simulação.

A partir dessas observações, parece-nos que a retirada do baço produz alterações no metabolismo lipídico e que as operações conservadoras atenuam ou mesmo impedem essas alterações. Nesse sentido, algumas indagações devem ser feitas e necessitam ser investigadas. $O$ que poderá ocorrer em animais esplenectomizados que se alimentarem de diferentes tipos de dieta? Quais seriam as repercussões das esplenectomias nas artérias de grosso e médio calibre no nível clínico e experimental? Quais seriam as influências das dietas e medicamentos em animais e em seres humanos esplenectomizados? Quais seriam os valores dos lípides plasmáticos em diferentes períodos de pós-operatório?

\section{Agradecimento}

Departamento de Apoio à Pesquisa Clínica e Experimental do Instituto de Desenvolvimento Sustentável (Instituto Solidário do Espírito Santo) pelo auxílio financeiro.

Conflito de interesse: não há.

\section{SUMMARY}

EFFECTS OF TWO TYPES OF DIET ON PLASMA LIPIDS IN RATS SUBMITTED TO SPLENIC SURGERY

OBJECTINE. The objective was to verify the effect of total splenectomy and ligature of the splenic vessels on the plasma lipid levels in rats fed a control diet or a diet supplemented with $2.5 \%$ cholesterol.

METHODS. Ninety-nine male Wistar rats weighting between 273 and $427 g$ (arithmetic mean: $349.46 \pm 35.54$ ) were randomly divided into four groups: group /- control ( $N=19)$, nonoperated; group 2 - sham $(N=19)$, laparotomy with spleen manipulation; group 3 -TS $(N=31)$, total splenectomy; group $4(N=30)$ simultaneous ligature of the splenic artery and vein. Blood was collected from all animals for determination of plasma lipids at the beginning of the experiment. Rats were than divided into two 
subgroups receiving either control diet (subgroup A) or diet supplemented with 2.5\% cholesterol (subgroup B). Another blood sample was collected 90 days later for a new determination.

RESULTS. No significant difference in plasma lipids between the four groups was observed at the beginning ( $p>0.05)$. In subgroups $I A, 2 A$ and $4 A$, there was no significant difference in the values of $H D L, V L D L$ and triglycerides, except $L D L$ that dropped significantly in subgroup $I A$ and $2 A(p<0.05)$ and not significantly in subgroup $4 A$. In subgroup $I B, 2 B$ and $4 B$ there was a significant increase in late postoperative plasma total cholesterol, $L D L, V L D L(p<0.05)$ and a not significant increase of HDL. In total splenectomy, at late postoperative there was a significant increase of cholesterol, $L D L$, VLDL and triglycerides, especially in subgroup B. In group 3 the cholesterol, LDL and triglycerides were more significant than in groups 1, 2 and 4.

CONCLUSION. Total splenectomy caused a more significant increase of cholesterol, LDL, VLDL and triglycerides in rats fed a cholesterol diet. The simultaneous ligature of vein and artery prevented alterations in plasma lipids observed in rats submitted to total splenectomy and maintained lipid levels similar to those of the control and sham groups. [Rev Assoc Med Bras 2007; 53(2): 171-7]

KEY WORDS: Adverse effects / splenectomy. Method / splenectomy. Splenic artery / ligature. Splenic vein / ligature.

\section{REFERÊNCIAS}

I. Resende LSR, Machado PEA. Complicações da esplenectomia. In: Petroianu A editor. O baço. São Paulo: Baliero Editores Ltda; 2003. p.302-6.

2. King H, Shumacker Jr HB. Splenic studies. Ann Surg 1952; 136: 23942.

3. Green JB, Shackford SR, Sise MJ, Fridlund P. Late septic complications in adults following splenectomy for trauma: a prospective analysis in I44 patients. J Trauma. 1986;26:999-1004.

4. Morris DH, Bullock FD. The importance of the spleen in resistance to infection. Ann Surg. 1919;70: 513-21.

5. Andersson R, Alwmark A, Bengmark S. Outcome of pneumococcal challenge in rats afte.splenic artery ligation or splenectomy. Acta Chir Scand. 1986; I52:15-7.

6. Robinete CD, Fraumeni JF Jr. Splenectomy and subsequent mortality in veterans of the 1939-45 war. Lancet. 1977:16:127-9.

7. Sugihara T, Yawata Y. Observations on plasma and red cell lipids in hereditary spherocytosis. Clin Chim Acta. 1984;137:227-32.

8. Aviram M, Brook JG, Tatarsky, Levy Y, Carter A. Increased low-density lipoprotein levels after splenectomy: a role for the spleen in cholesterol metabolism in myeloproliferative disorders. Am J Med Sci. 1986:291:25-8

9. Asai K, Kuzuya M, Naito M, Funaki C, Kuzuya F. Effects of splenectomy on serum lipids and experimental atherosclerosis. Angiology. 1988;39:497504

10. Fatouros M, Bourantas K, Bairaktari E, Elisaf M, Tsolas O, Cassioumis. Role of the spleen in lipid metabolism. Br J Surg. 1995; 82:1675-7.

I I. Paulo DNS, Lázaro da Silva A. Lipídios plasmáticos após esplenectomia total e parcial em cães. Rev Col Bras Cir. 2001;28:264-70.

12. Silva MM, Jamel N, Refinetti RA, Oliveira MAS, Padilha MS. Papel do baço no perfil lipídico: - estudo experimental. Arq Bras Cir Dig. 2002; | $5: 12 \mid-4$.

13. Petroianu A, Veloso DF, Costa GR, Alberti LR. Effects of splenic surgeries on lipidogram of rats. Rev Assoc Med Bras. 2006;52:56-9.

14. Conti S. Splenic artery ligation for trauma. An alternative to splenectomy.
Am J Surg. 1980;140:444-8.

15. Keramidas DC, Soutis M. The function of the spleen in adults after ligation of the splenic artery of the traumatized spleen in childhood. Surgery. $2003 ; 133: 583-5$

16. Orozco H, Mercado MA, Martinez R, Tielve M, Chan C., Vasquez M, et al. Is splenectomy necessary in desvascularization procedures for treatment of bleeding portal hypertension? Arch Surg. 1998;133:36-8.

17. Abbas MA, Stone WM, Fowl R J, Gloviczki P, Oldenburg WA, Pairolero PC et al. Splenic artery aneurysms: two decades experience at Mayo Clinic. Ann Vasc Surg. 2002;16:442-9.

18. Witte CL, Corrigan JJ Jr, Witte MH, O'Mara RE. Splenic artery ligation in experimental hypersplenism. Surgery. 1976;80:58।-5.

19. Sahin M, Tekin S, Aksoy F, Vatansev H, Seker M, Avunduk MC, et al. The effects of splenic artery ligation in an experimental model of secondary hyperesplenism. J R Coll Surg Edinb. 2000;45:|48-52.

20. Lin PW, Shan YS. Effects of splenectomy and splenic artery ligation on the portal presure in portal hypertensive rats. J Surg Res. 1992;53:621 24.

21. Alwmark A, Bengmark S, Christensen P, Gullstrand P, Schalen C. Increased susceptibility to pneumococci after ligation of the splenic artery in experimental hypersplenism. Eur Surg Res. 1983;15:92-6.

22. Anderson R, Alwmark A, Bengmark S. Influence of dextran on pneumococcal septicemia in splenic artery-ligated or splenectomized rats. Res Exp Med. 1987; 187:423-7.

23. Tanaka T, Ichiba Y, Fujii Y, Itoh H, Kodama O; Dohi K. New canine model of chronic pancreatitis due to chronic ischemia with incomplete pancreatic duct obstruction. Digestion. 1988;41:|49-55.

24. Feigenberg Z, Abramovici A, Zer M, Wolloch $Y$, Nathan H, Dinstman $M$. Assessment of splenic function in dogs following arterial ligation and autotransplantation. Isr J Med Sci. 1985;21:579-83.

25. Ortyl W, Turowska B, Ciazynski M, Zarborski G, Turowski G. Anti$\mathrm{N}$ antibodies after ligation of splenic artery in rabbits. Mater Med Pol 1989;21:35-7.

26. Warshaw AL. Conservation of the spleen with distal pancreatectomy. Arch Surg. 1988;123:550-3.

27. Gramatica L, Lada PE, Gramática LH, Dutari CH, Diyorio G. Conservação do baço durante a pancreatectomia córporo-caudal. Rev Col Bras Cir. 1995; 222:227-9.

28. Ueno T, Oka M, Nishihara K, Yamamoto K, Nakamura M, Yahara N, et al. Laparoscopic distal pancreatectomy with preservation of the spleen. Surg Laparosc Endosc Percut Tech. 1999;9:290-3.

29. Paulo DNS, Kalil M, Grillo Jr LSP, Borges EB, Cintra LC, Pereira FEL, et al. Viabilidade do baço de ratos após a ligadura dos vasos esplênicos: Efeito do tratamento com oxigênio hiperbárico. Rev Ass Med Bras, 2005; $51: 46-50$.

30. Ellis $\mathrm{H}$. The aetiology of post-operative abdominal adhesions. An experimental study. Br J Surg. 1962;49:10-6

31. Touloukian RJ, Dang CV, Caride V]. Splenic function following experimental dearterialization injury in the sucking rat. J Pediat Surg. 1978; |3:13135.

32. Morais AAC. Soja. In: Lameu S, editor. Clínica nutricional. Rio de Janeiro: Revinter Livraria e Editora ; 2005. p.569-87.

33. Bradshaw P H, Thomas CG. Regeneration of splenic remnant after partial splenectomy in rats. J Surg Res. 1982;32:176-81.

34. Van Wick DB, White $M H$, White CL. Critical splenic mass for survival from experimental pneumococcemia. J Surg Res. 1980;28:14-7.

35. Caligiuri G, Nicoletti AP, Poirier B, Hansson GK. Protective immunity against atherosclerosis carried by $\mathrm{B}$ cells of hypercolesterolemic mice. J Clin Invest. 2002; 109:745-53

36. Hartmut $H$, Siegfried W. The spleen as a storage pool in lipid metabolism. Am J Gastroenterol. 1997;92:1072.

Artigo recebido: 21/07/06

Aceito para publicação: 19/10/06 